\title{
GEPHALIC DYSOSTOSIS
}

\author{
BY \\ Clifford alleN, Colney Hatch Mental Hospital
}

INTRODUCTION

IT is not unusual in neurology and psychiatry to discover that signs which have at first been considered minor assume on further investigation paramount importance. Nice examples of this are found in the Argyll Robertson pupil and the extensor plantar reflex. It is possible therefore that those inconsiderable variations in structure which have been labelled ' stigmata of degeneration' may with the growth of knowledge at least repay us for the trouble of investigation. The importance acquired by acromegaly which was first regarded as a curiosity should emphasize this fact. The association of epilepsy and amentia-both rather mysterious conditionswith variations in cephalic structure compels us to regard these anomalies as the result of disease-processes capable of being understood.

A number of morbid states, some sporadic and some familial, have been described, all of which are characterised by anomalous development of the skull. Some of these have been associated with somatic variations elsewhere. It is these disease-conditions which it is proposed to classify together under the title of 'Cephalic Dysostosis,' and it is hoped to show that they may depend on a common pathogeny. The morbid conditions which form this group are oxycephaly, acrocephalosyndactyly of Apert, the hypertelorism of Greig, the craniofacial dysostosis of Crouzon, scaphocephaly, trigonocephaly and plagiocephaly. Microcephaly, arachnodactyly, and cranio-cleido-dysostosis are not included, since it will be seen when an attempt is made to define the characteristics of this group that these affections are not admissible.

The conditions classified here as cephalic dysostosis are supposed to result from premature synostosis of the skull bones. This ætiology has never been subjected to criticism, which is curious, since disease of the soft parts is a frequent concomitant. The contention of this paper is that the affections concerned are the result of temporary retardation or even cessation of the growth of the brain, which allows premature synostosis and consequently distortion of the skull when the brain resumes growth.

\section{RÉSUMÉ OF DISEASE-GONDITIONS GONGERNED}

A short description will be given and the theory of their ætiology will be described.

Oxycephaly was first described by von Graefe ${ }^{1}$ in 1866. It is characterized by a high tower-like skull, exophthalmos, strabismus (usually divergent) 
and nystagmus. The supraorbital ridges, glabella and frontal eminences of the skull are obliterated. The increased intracranial pressure is frequently shown on skiagrams by digitations and clinically by severe headaches and optic atrophy. The association of oxycephaly and syndactyly is fairly common and has been named by Apert ${ }^{2}$ acrocephalosyndactyly.

Hypertelorism is a rare state which was described by Greig ${ }^{3}$ in 1924 . It is characterized by excessive width between the eyes, a retroussé nose with a broad bridge and widely open nasal passages, strabismus (usually divergent) and prognathism.

Craniofacial dysostosis was first described by Crouzon ${ }^{4}$ in 1912 . It is characterized by a central frontal boss, a beak-like nose, prognathism, exophthalmos and strabismus. Scaphocephaly is produced by a narrow skull with a sagittal ridge. Trigonocephaly is excessive scaphocephaly producing a triangular skull. Plagiocephaly is asymmetry of the skull caused by unequal growth of one of the lateral halves. This produces an unequal, lopsided appearance.

Cases have been described of all these conditions (except perhaps plagiocephaly) in which they occur in familial and hereditary incidence. Craniofacial dysostosis is according to Crouzon practically always hereditary, but Comby (quoted by Crouzon) records a solitary case. Oxycephaly is usually described as occurring sporadically, but cases have been recorded in which it has been inherited in certain families. A few familial cases of scaphocephaly have been reported. Any of these states appear to be capable of producing signs of increased intracranial pressure varying from the mild headaches in Crouzon's cases to the severe headaches with vomiting occurring in oxycephaly. Epilepsy occurs in some. A large number of patients with hypertelorism, scaphocephaly or trigonocephaly suffer from epilepsy. It is tempting to attribute the epilepsy and the amentia which so frequently accompanies this group to the increased intracranial pressure, but this is not justified. It is in oxycephaly that the intracranial pressure is highest and yet oxycephalics are frequently of normal mentality. In hypertelorism the intracranial pressure is not necessarily much raised above the normal, yet in this condition fits and amentia are common. It is necessary therefore to appreciate that the morbid process is not confined to the bones or sutures, as has generally been affirmed.

The incidence of amentia in these cases can be correlated with the tendency to epilepsy, since in craniofacial dysostosis (where the mentality is usually normal) epilepsy is rare, and it did not appear in Crouzon's cases except as infantile convulsions. Conversely, in hypertelorism epilepsy and amentia are both common.

Anyone who has examined skiagrams of these conditions must feel convinced that they belong to a common group. Moreover, the fact that they are occasionally intermixed (as in Chotzen's 5 case, which showed acrocephalosyndactyly, hypertelorism, and dysostosis craniofacialis ; in Roubino. 
vitch's case-quoted by Crouzon-of craniofacial dysostosis with trigonocephaly, and Lesne's ${ }^{6}$ case of craniofacial dysostosis and oxycephaly combined) suggests that one disease-process may be at the root of these curious anomalies. The morbid process affects now one part of the skull and now another; hence the variations produced appear to be different states, although in reality they are only manifestations of one pathology.

\section{PATHOGENESIS}

In the past it has been the custom to attribute such affections to ' degeneration.' Many of these patients, however, are of normal mentality. Other writers have been dissatisfied with the vague word 'degenerate' and have evoked the process of 'blastophoria' as though this would save further intellectual and clinical effort. It is true that gross poisoning with lead and other toxins or that violence to the ovum may lead to the production of monsters, but it is very doubtful whether the embryo is ever subjected to such a severe environment during intrauterine life. Moreover, the published cases of hypertelorism contain only one instance in which a parent was alcoholic or otherwise diseased. The presence of parental disease in oxycephaly, acrocephalosyndactyly, or craniofacial dysostosis is also rare. Before one can accept the blastophoric origin of these conditions much more evidence must be produced.

Jansen ${ }^{7}$ would argue that the cause is the pressure of the amnion upon the fotus and even gives a table suggesting the anomalies produced by applying pressure at various dates. For instance, application of pressure in the second and third week produces anencephaly, in the fourth to the fifth week acrocephalosyndactyly, in the seventh week mongolian idiocy, and so on. This theory is a mass of assumptions and may be dismissed as not only unproved but very unlikely to be correct. In comparison with acromegaly and cretinism it is tempting to seek a glandular basis, but although Crouzon described a slight goitre in his first case of craniofacial dysostosis none of his other cases showed any glandular disease. The cases of hypertelorism which have been described have usually been in children who have not appeared to be suffering from glandular troubles. We cannot therefore accept a frank endocrine basis for these conditions such as we find in acromegaly.

Crouzon explains the premature fusion of sutures in craniofacial dysostosis by Mendelism. He thinks that the disease is a recessive and explains its rarity in this way. However, it appears to occur occasionally as a mutation and breeds as a dominant. Oxycephaly is usually explained as being due to 'inflammation' causing premature synostosis. No signs of this 'inflammation' have ever been seen nor any reason for its occurrence been produced. Moreover, 'inflammation' is associated with hyperæmia, whereas synostosis usually occurs with diminished blood supply-for example, in old age. 
Greig pointed out that the reason for the widely separated eyes in his cases appeared to be the development of that part of the sphenoid which is laid down in cartilage, so that the lesser wings grow as large as or larger than the greater wings. Greig, Reuben and Fox, ${ }^{8}$ Ogilvie and Pozel ${ }^{9}$ all point out that scaphocephaly is due to underdevelopment of the great wings of the sphenoid. In oxycephaly the greater wings are enlarged. No explanation is produced for these curious variations in sphenoidal growth.

Crouzon believes that craniofacial dysostosis is due to the premature fusion of certain sutures (he does not state exactly which ones), and that the subsequent deformities are caused by an effort to accommodate the growing brain. He points out that the patients with the most deformed skulls suffer least from increased intracranial pressure. He divides the process into three stages : (1) stage of premature fusion of the sutures ; (2) stage of deformity to accommodate the brain ; (3) stage of increased intracranial pressure. It will be seen that he regards the disease as being basically one of the bony parts - the sutures.

\section{PERSONAL THEORY}

I believe that these explanations are incomplete mainly because they are based on the study of the bones to the neglect of the brain.

It has been admitted since the failure of operative measures in microcephaly that the growth of the skull is dependent on the growth of the brain. In microcephaly the brain does not grow to the usual size and the skull shapes itself to conform to it. On the contrary, in macrocephaly the skull grows large to accommodate the larger brain. Again, in porencephaly the skull is often flattened over the undeveloped half of the brain. It will therefore appear probable that any deformity of the skull is the result of cephalic disease and not of disease of the bones or sutures. For some unknown reason the fotal brain does not develop at the normal rate and in the normal directions. Possibly the brain even stops growing for a time. This uneven development allows the sutures to fuse where they are in contact. Possibly the normal stimulus for the junction of the sutures is the cessation of stimuli from the growing brain when it has reached an appropriate size. It is true, as Greig says, that in oxycephaly ' where the bones touch they fuse,' but the bones should not come into contact, and if the brain is growing normally they have no time to fuse. In cephalic dysostosis the brain, as it were, hesitates and is lost.

We are now in a position to understand the various cranial anomalies which have been considered hitherto as different morbid states.

Whether oxycephaly, hypertelorism, craniofacial dysostosis, trigonocephaly or any other member of the group is produced will depend on which part of the brain is sluggish in its growth. If it is mainly the frontal lobes which are affected, so that the coronal sutures are allowed to fuse (possibly other sutures also fuse), the brain will find itself forced to enlarge the skull upwards, producing oxycephaly. If the parietal lobes are at fault then 
scaphocephaly is produced. Hypertelorism and craniofacial dysostosis appear dependent on disproportionate growth of the occipital and possibly other lobes (this may explain the abrupt occiput in hypertelorism).

It is in plagiocephaly that this explanation is shown most clearly. Here the skull is underdeveloped on one side so that it is markedly asymmetrical. The writer believes that this is due to temporary cessation of growth of the whole of the telencephalon on the affected side. This is demonstrated by the fact that in porencephaly (where the whole telencephalon on one side may be replaced by a cyst) there is a similar skull defect on the affected side. Moreover, if the unilateral defect were caused by premature fusion of one coronal suture one would expect that the growing lateral lobe would cause displacement of the third ventricle, such as one finds in cerebral tumours of one cerebral lobe. That this displacement does not occur is shown in Jacobsen's 10 case. Unfortunately no reliable series of plagiocephalic brains has been examined, so that the question cannot be finally settled on this evidence. It is a justifiable question to demand why the brain should stop growing and then start again while the child is still in utero. There seem two possible explanations. (1) Either the mother or child is born with a poor glandular equipment which tends to become exhausted and then recover at some period during parturition. (2) Some toxic influence interferes with the cerebral growth of the embryo.

The glandular theory is not necessarily incompatible with Mendelian views and is upheld by one remarkable fact. In anencephaly where the skull does not grow-possibly because there is no cephalic stimulus-there are anomalous adrenal bodies. This was first noticed by Morgagni in 1723, who recorded that the adrenal glands in anencephalics were small but not absent. In 1910 Elliot and Armour ${ }^{11}$ discovered that this was due to the absence of foetal adrenal cortex so that the adrenals of anencephalics approximate to the adult type. Boyd ${ }^{12}$ has since confirmed this and the fact may be considered to be well established. The foetal brain is apparently dependent on some product of the adrenal bodies (unless it is vice versâ).

The toxic theory cannot be dismissed without consideration. No little evidence can be produced in its favour. For instance, oxycephaly is a fairly frequent concomitant of hæmolytic jaundice occurring in children (Feingold and Case, ${ }^{13}$ Mikulowski ${ }^{14}$ ). It is possible that this produces a toxic encephalitis or affects the brain by poisoning the glands primarily.

Bronfenbrenner ${ }^{15}$ records a case in which a woman was forced to leave Alaska because it was feared that the lack of fresh food would affect her pregnancy. She left Alaska in the later months of gestation and eventually gave birth to a child suffering from acrocephalosyndactyly. Whether this was due to toxic conditions or lack of vitamines it is difficult to say.

The syndactyly which occurs in Apert's disease is frequently put forward as proof that this condition is one of the bones. It seems probable that the fusion of the fingers and toes may be due to deficient innervation of these 
parts. It will be noted that the arms and legs do not fuse but only the distal parts, which need more delicate innervation to move them. Moreover, it is in oxycephaly-a condition in which it is postulated that the frontal lobes are affected and which would lead to loss of spontaneous movement-that fusion occurs. It appears probable that the fingers and toes are normally prevented from fusion in early intrauterine life by their spontaneous movement ; otherwise it would seem that pressure would interfere with the blood supply and would inevitably cause fusion in such a closely packed organism. Any condition of the brain leading to immobility of the fingers and toes would lead to their fusion before birth and may be the explanation of the occasional occurrence of these deformities in cases of simple amentia. This fact is upheld by the cases in which the fingers and toes are fused only by their soft partsfor example, the toes in Bostock's ${ }^{16}$ and Johnstone's ${ }^{17}$ cases. This in my opinion makes it difficult to believe that the disease is one of bony origin. Poor innervation with loss of spontaneous movement during intrauterine life may explain the occurrence of genu valgum (such as appears in the case recorded below) and similar deformities of the elbow, which Apert calls ' acrocephalosynankie.'

The myopia which is a frequent concomitant of cephalic dysostosis must be regarded as another proof that the disease is one of the soft parts and not of bony origin. Whether the myopia is present at infancy or has any connexion with the aberrant growth of the nervous tissue or the increased intracranial pressure is uncertain. The anosmia which sometimes occurs may be the result of cerebral disease, the increased intracranial pressure, or pressure from the distorted skull, but which is the causal factor it is difficult to say.

We may define cephalic dysostosis as a distortion of the skull caused by increased intracranial pressure due to abnormal growth of the brain allowing premature synostosis. That there is a Mendelian factor present appears probable, but the object of this paper is to suggest that the primary disease is one of the brain rather than the bone. The Mendelian theory is not incompatible with the glandular or toxic theories, but indeed in some cases no Mendelian factors are discoverable. The case recorded below occurred in such a large family of siblings that even a recessive had ample opportunity of appearing more than once.

It is admitted that we have carried the investigation of the pathogeny only one step further back, yet the advantages of this theory of causation are obvious. It brings the whole rather chaotic collection of facial and cranial deformities into one orderly classification and offers one explanation for their occurrence. Moreover, it suggests prophylactic measures which theories of fundamental bony disease have caused to be regarded with apathy and despair.

\section{PERSONAL GASE}

This case is one of hypertelorism occurring in a woman of 58 and accompanied by amentia, epilepsy, and a paranoid psychosis. 
Family History. - I am informed by the patient's sister that family albums-now unfortunately no longer extant-showed the patient's ancestors on both her mother's and her father's side back to her great-grandfathers. No abnormality is said to have been present in these people.

The patient's father married at 23 , and by this wife had the following normal children.

1. William. He died at the age of 60 with a cerebral tumour.

2. Rose. She is still alive, aged 75, with 10 children, eight of whom are alive.

3. Charlotte. She was crippled through a fall while pregnant. She died aged 56.

4. Millicent. Still alive, aged 70. She has three children. One died from (?) spinal caries. The other two are alive, married, with healthy children.

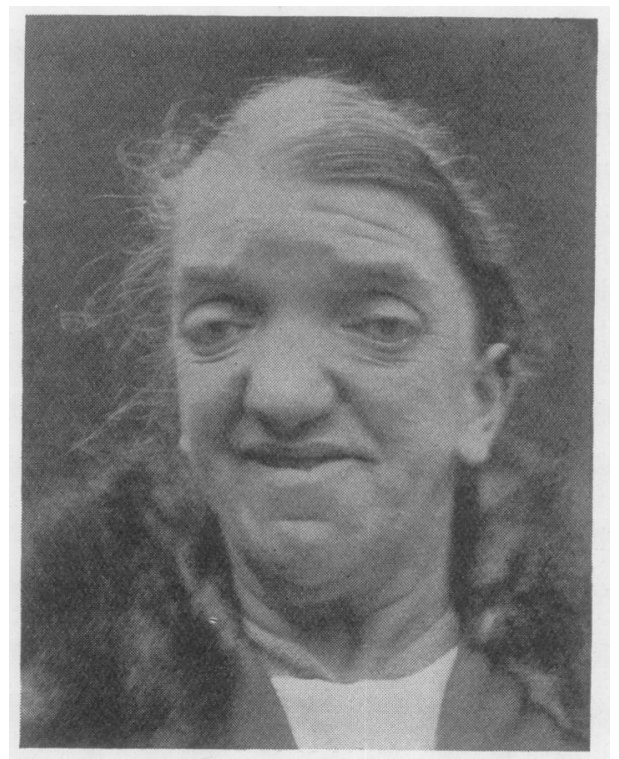

Fig. 1.-Note the widely separated eyes and contour of the skull.

5. James. Died aged 18 from phthisis.

6. Frederick. Alive, aged 65, one son married.

The patient's father's first wife died at the age of 40 and he married again, a woman aged 23. She was not consanguineous. The children of this union were :

1. Edith. The patient.

2. Lousa. Alive, aged 54. No children.

3. George. Alive, aged 53, single.

4. Charles. Alive, aged 51. Two children, one a girl who is married, with one healthy child. children.

5. Violet. Alive, aged 50, with six children-one son is married, but with no

6. Henry. He died aged six months from vaccinia.

These children were followed by three premature births. The cause of this is unknown. None of these people-other than the patient-has suffered from hypertelorism, amentia, or insanity as far as can be ascertained. 
Personal History.-The patient was a full-time child. The labour was protracted and instruments were used. She was noticed to have peculiar facial conformation after birth. She is said to have been a bright happy little child and got on well at school although she did not reach higher than the sixth standard when she left at the age of 14. At the age of 17 she started to suffer from petit mal attacks which were thought to be fainting fits and no medical advice was sought on their account. Her husband describes how these attacks would occur in the midst of some domestic duty such as laying the table or arranging crockery on the dresser. After the momentary interruption she continued her occupation where it had been left off.

She married at the age of 32 and gave birth to a normal child two years later. She then started to suffer from grand mal attacks. These appeared at the menstrual

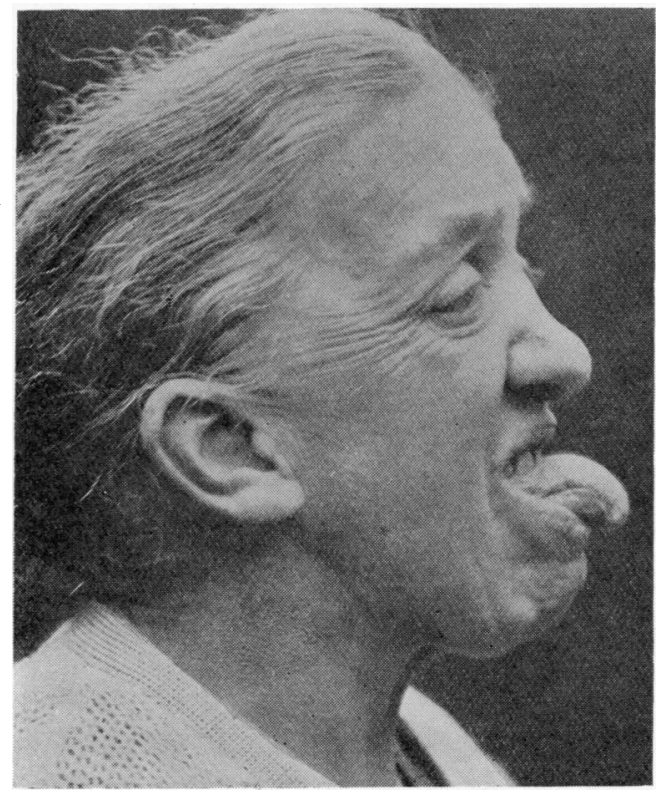

Fig. 2.-Note the humped-up tongue caused by the prognathism.

periods and were usually nocturnal. They were preceded by an aura of suffocation. She did not consider these attacks sufficiently severe to merit treatment.

Six years ago she fell downstairs in a fit and was badly concussed. As she is said to have been unconscious for two and a half days it is probable that some cerebral damage-possibly vascular-was present. When she recovered consciousness she was noticed to behave abnormally. Her sister states that "when she came round she behaved like a mad woman. She talked in a nasty sharp way and pulled you about. She would say to me, "I don't want you-go home.", She grew worse for three years, becoming more and more hostile and persecuted. She became hallucinated and screamed for no apparent reason. In 1930 when she became violent the family were forced to send her to the local infirmary where she was disorientated, impulsively violent, and noisy. She stated that she could hear her sister calling to her. She was certified and sent to Bexley.

On admission she was noted to be disorientated, confused and resistive. She stated that people were discussing her and kept putting out her light. She felt that 
there were plots against her and was very complaining, querulous, and dissatisfied. Every day she complained of physical violence and of attempts to ' do her in.' She was described as being degenerate in appearance, but was not recognized as suffering from hypertelorism.

She recovered after being in Bexley for approximately two months, having little memory of the acute phase of her illness. She had two fits while in Bexley, but no note was made of their type.

She remained comparatively well until September 1933, when she complained of hallucinations of smell and taste, thought that her bed was haunted and that ammonia was being sprinkled on her. She became agitated and depressed, and was again certified and sent to Bexley.

She was admitted by the writer who recognized her as a case of hypertelorism, but on admission she was too noisy and violent to allow a proper physical examination.

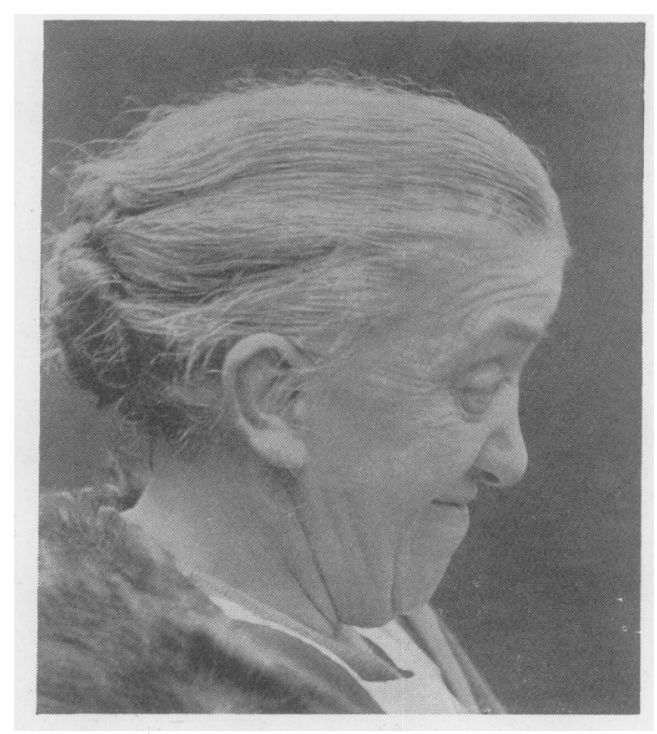

Fig. 3.-Note shape of skull.

She suspected that the physical examination was an attempt at sexual and physical assault and shouted 'You're not going to murder me, are you ?' She kept shrieking that she had been examined by a black doctor, that patients were being blinded in hospital for their money, and that everything stank of ammonia.

She appeared in rather a Korsakovian state of disorientation with confabulation two days after, and stated that she had been for a motor ride. She was still suspicious and said to me, 'You're not going to petrify me, are you ?' Since this she has passed through a slight euphoric stage hardly amounting to hypomania, a stage of confusion and quiet contented stages. Since admission she has had occasional fits-about four per month-but these are now controlled by luminal.

Physical Condition.-She is a rather stocky woman, $4 \mathrm{ft} .11 \frac{1}{2}$ in. in height. Her cranial condition is well shown in the accompanying photographs. She has a rather scaphoid, dolichocephalic head without the abrupt occiput commonly associated with hypertelorism. The top of the skull is slightly triangulated anteroposteriorly and laterally. The eyes are widely spaced with the palpebral fissures sloping somewhat downwards laterally. There is some ptosis and some exophthalmos. The nose shows 
the characteristically wide base with a flattened bridge and broad tip. The nasal passages are large and the nasolabial folds deeply marked. The mouth is fairly normal, but the lips are thin. The mandible projects and the teeth are prognathic, irregularly spaced, and do not meet those of the upper jaw. The ears are not a good shape, but would pass for normal on a normal head. She has no other somatic abnormality except for genu valgum of the right knee. It is interesting to note that Montford's ${ }^{18}$ case of hypertelorism showed a similar deformity.

Mr. P. M. Moffatt, the consulting ophthalmologist, kindly examined her eyes and reported on them. He found a divergent strabismus, and slight nystagmus which is

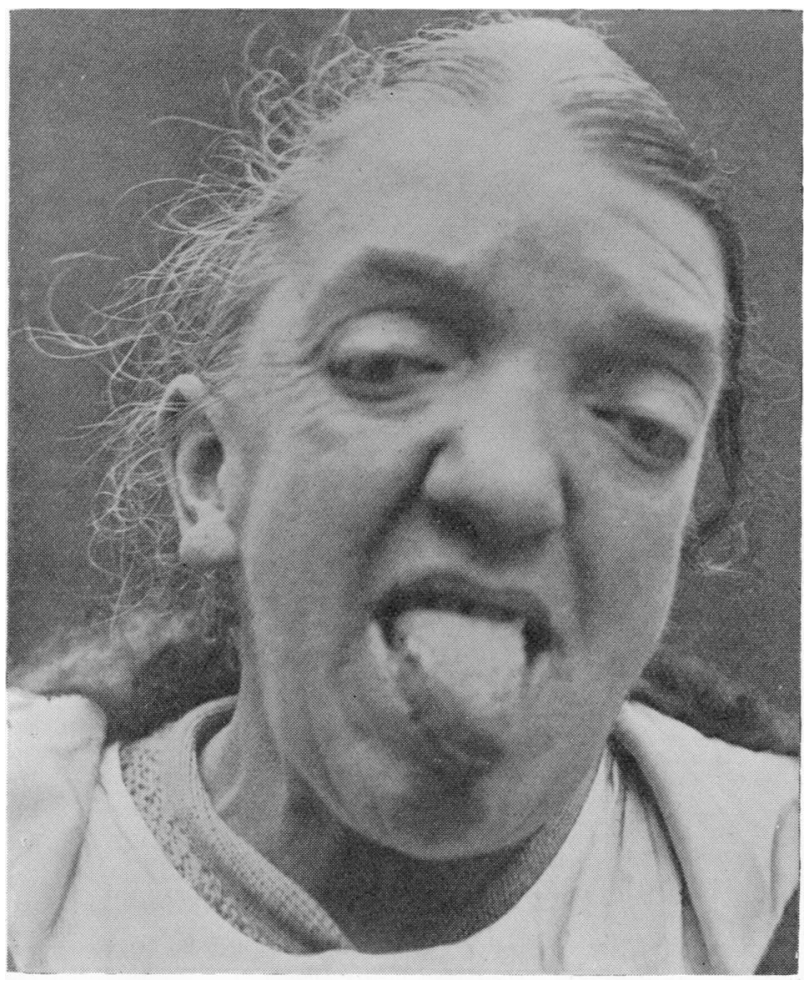

Fig. 4.- Note the shape of the skull, the ptosis, strabismus and slant of the eyes. The broad bridge of the nose is well shown, and the humped-up shape of the tongue on protrusion.

not always present. The right fundus showed a blurred margin to the disc and narrowing of the vessels. There was a patch of choroidoretinal atrophy below and a smaller similar patch above the disc, also a little scattered fine choroidoretinitis which was thought to be of old standing. 'Vitreous floaters' were present and slight early peripheral lens striæ. The left fundus showed similar changes but not so marked. Myopia .was found to be present in each eye, about $4 \mathrm{D}$., but she was able to read only 5/60 distance. She could read Jaeger 3 with each eye without glasses. The movement of the eyes was found to be normal, but her convergence was poor-possibly because of her exophthalmos. She had some bilateral ptosis. Her eyes reacted to light and accommodation. 
The other cranial nerves were examined and her sense of smell was found to be very poor. She said that oil of lavender smelled 'very strong like ammonia,' and that asafœetida smelled of vinegar.

The fifth nerve is normal and the sense of taste appears normal. The face moves normally and hearing is good. Ninth, tenth, eleventh, and twelfth nerves show no abnormality.

No abnormality was discovered in the rest of the nervous system.

The cerebrospinal fluid was taken and the Wassermann and Meinicke reactions found to be normal. Unfortunately the pressure was not taken. I have tried since to do so but was prevented by a dry tap.

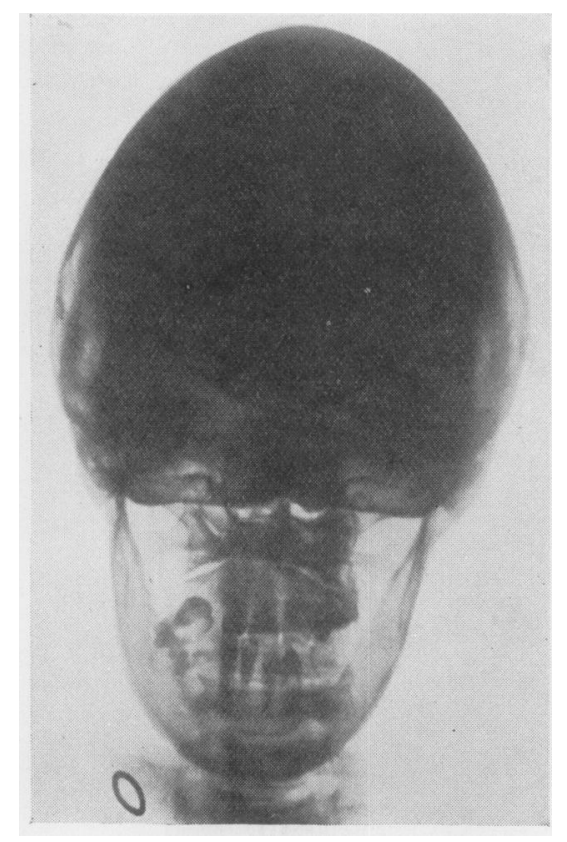

Fig. 5.-Anteroposterior X-ray picture of skull. age.

The other systems are normal. Her blood pressure is $120 / 80$, which is low for her

Intelligence Tests.-She did not co-operate well and was inclined to let her attention wander. She was more successful in concrete than in abstract tests.

$\begin{array}{llllllll}\text { Binet Simon } \ldots & \ldots & \ldots & \ldots & \ldots & \ldots & \ldots & \text { M.A. 8·4/12. } \\ \text { Burt's Graded Reasoning test } & \ldots & \ldots & \ldots & \ldots & \ldots & \text { M.A. 7. }\end{array}$

Porteus tests were unsuccessful owing to her poor sight.

She reads fairly well and has some idea of what she has read.

Measurements.-The measurements of her skull are of interest.

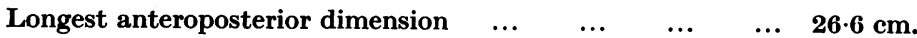

$\begin{array}{llllllll}\text { Greatest breadth } & \ldots & \ldots & \ldots & \ldots & \ldots & \ldots & \mathbf{1 4 . 3} \mathbf{~ c m} .\end{array}$

$\begin{array}{lllllllll}\text { Cephalic index } & \ldots & \ldots & \ldots & \ldots & \ldots & \ldots & \ldots & \mathbf{7 0} .\end{array}$

The skull is therefore dolichocephalic.

\begin{tabular}{lllllll} 
Interpupillary distance $\ldots$ & $\ldots$ & $\ldots$ & $\ldots$ & $\ldots$ & $\ldots$ & $8 \cdot 3$ \\
\hline
\end{tabular}

Normal $=\mathbf{6} \cdot \mathbf{0}$. 


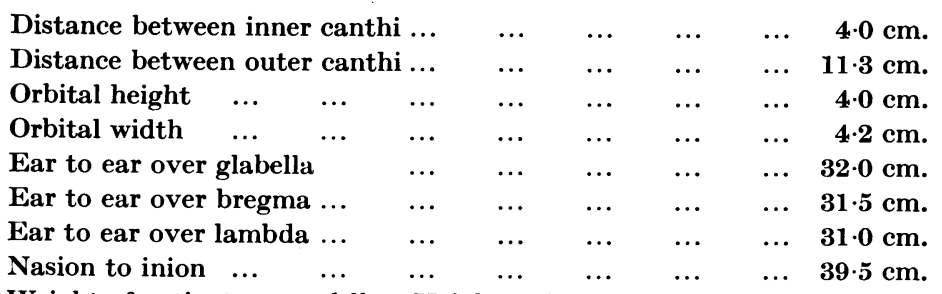

Weight of patient, 8 st. $9 \frac{1}{2} \mathrm{lb}$. Height, $4 \mathrm{ft}$. $11 \frac{1}{2}$ in.

The skiagrams are of much interest. The lateral view shows the greatly elongated dolichocephalic appearance one would expect. The frontal bone is somewhat abrupt and the anterior end of the head is rather square, but true oxycephaly is not present.

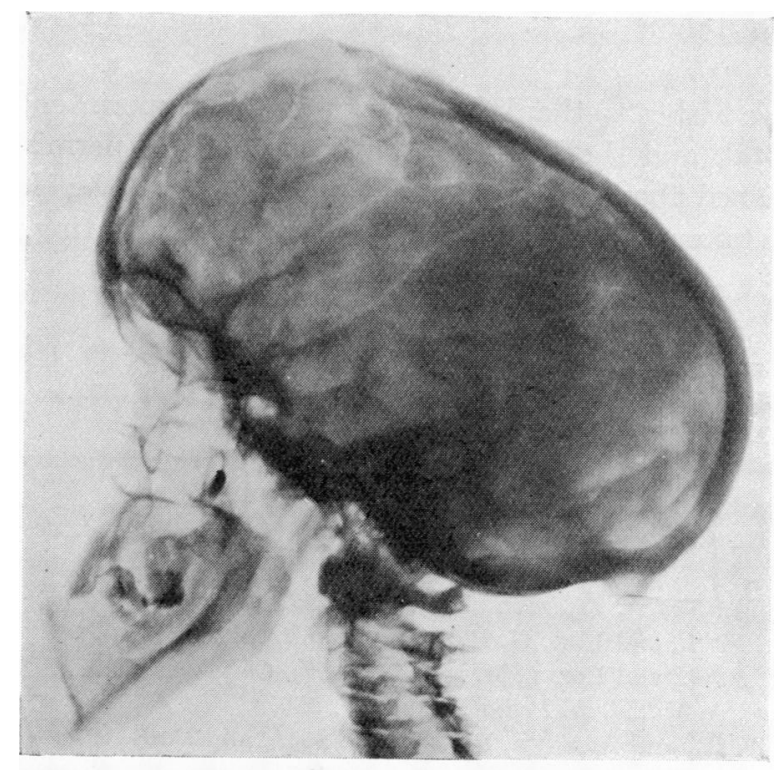

Fig. 6.-Lateral X-ray picture of skull.

The occiput is not flattened as it usually is in hypertelorism. The bone over the posterior end of the skull is thick and solidly formed. There is a curious appearance over the point of junction of the frontal and parietal bones. There is an area of rarefaction, or of separation of the external and internal tables of the skull, which almost looks as though an air sinus had been inserted there. This appears to be the vestigial remains of the anterior fontanelle. The base of the skull is so distorted that it is difficult to be sure if the sella is abnormal. There is evidence of old increased intracranial pressure in the stippled 'beaten-silver' appearance of the skull. The prognathism and the large irregular teeth are well seen. There appears to be slight distortion of the upper vertebræ, probably due to the unbalanced cumbersome skull.

The anteroposterior view is very dark because of the immense length of the skull. The widely separated orbits are well seen. The large irregular teeth show up well in the upper and lower jaws.

The patient has a daughter who is apparently normal both in appearance and mentality. She was born after a normal labour and was breast-fed. There is nothing 
of interest in this girl's childhood. After she left school she worked as a milliner but married eight years ago and gàve birth to a normal child six years ago. This child-a boy-appears normal and is quite bright. I have had no opportunity of applying mental tests or examining physically either the child or the mother.

This is the first case of hypertelorism recorded in the literature in which the condition has been associated with schizophrenia or any other psychosis. It is doubtful if these conditions are related; psychological factors appear to influence her psychotic state, if they are not causal. Her hostility to her sister is apparently founded on the fact that her husband courted her sister at the same time that he paid attention to her. She makes no mention of her facial condition in her psychotic episodes although it is known she is rather sensitive about it.

The writer wishes to thank Dr. Clark, Medical Superintendent of Bexley Mental Hospital, and the London County Council for permission to utilize the case published above, also Mr. Sands, pharmacist to the Hospital, for the trouble he has taken in photographing the patient and printing the skiagrams.

\section{REFERENGES}

1 Von Graefe, Arch.f. Ophth., 1866, 114, 12.

2 Apert, E., Bull. et mém. Soc. méd. hóp. Paris, 1926, 50, 1432.

3 Greig, D. M., Edin. Med. J., 1924, 31, 560.

4 Crouzon, O., Études sur les maladies familiales nerveuses et dystrophiques, 1929.

5 Chotzen, F., Monats. f. Kinderh., 1932, 55, 97.

- Lesné, E., Clement, R., and Gilbert-Dreyfus, Bull. Soc. de pédiat. de Paris 1928, 26, 488.

7 JANSEn, M., Nederl. Tijdschr. v. Geneesk., 1928, $2,864$.

8 Reuben, M. S., and Fox, H. R., Arch. Pediat., 1928, 45, 105.

9 Ogilvie, A. G., and Pozel, M. M., Arch. Dis. Childhood, 1927, $2,146$.

10 Jacobsen, A. W., Arch. Pediat., 1930, 47, 556.

11 Elliot, T. R., and Armour, R. G., Jour. Path. and Bact., 1910-1911, 15, 481.

12 Boyd, W., Pathology of Internal Diseases, 1931, 470.

13 Feingold, B. F., and Case, J. T., Amer. J. Roentgenol., 1933, 29, 194.

14 Mikulowski, V., Arch. méd. d. enf., 1928, 31, 31.

15 Bronfenbrenner, A. N., Amer. J. Dis. Child., 1931, 42, 837.

16 Bostock, J., Med. J. Australia, 1928, 1, 572.

17 Johnstone, G. G., Lancet, 1932, $2,15$.

18 Montrond, T. M., Arch. Dis. Childhood, 1929, 4, 381. 